\title{
Do Chinese Private College Students Have Identity Stigma? The Development of Its Questionnaire and the Survey in Fujian Province
}

\author{
Weiling Cai ${ }^{1,2}$ \\ ${ }^{1}$ School of Humanities and Communication, Yango College, Fuzhou 350012, China; \\ ${ }^{2}$ School of Education and Applied Languages, Mingchuan University, Taoyuan 330, Taiwan.
}

Keywords: Private College; College Students; Identity Stigma.

\begin{abstract}
The Study developed the Private College Students' Identity Stigma Questionnaire (PCSISQ), which was designed to measure the subjective experience of being a private college student, with dimensions measuring Stereotype, Internalized Stigma, Drawback Behavior and Stigma Resistance. Results showed that PCSISQ had good reliability and validity, which could be an effective tool on measuring private college students' identity stigma. The researcher also investigated 895 private colleges in Fujian Province by using PCSISQ. The survey results suggested that the private college students do have considerable high level of identity stigma as being private, which was so different from the same group in western countries. Furthermore, female students were found suffering greater level than male ones on the Stereotype and Internalized Stigma dimensions.
\end{abstract}

\section{Introduction}

According to the definition of Goffman[1] ,Stigma is a multi-component concept involving processes of labeling, stereotyping, social exclusion, loss of status, and discrimination, all taking place within a context of differential power between the stigmatizing and stigmatized group. Stigma is a demeaning and insulting label which the society put on these individuals or groups, and the process of stigmatization is actually the process in which the stigmatized groups suffer exclusive responses as they have an "impaired identity". Studies have been rather focused on the "disease stigma" at home and abroad[2], such as the people with HIV infection, or mental disorders, or STD and those seeking psychological help. Besides that, some stigmatized groups with distinctively local characteristics have also gained much attention, such as the U.S. "Star Trek" fan group, and the infertile female Moslem group. Although stigma research gets started rather late in China, there have been studies on local Chinese stigmatized groups, such as China's rural worker and urban immigrant groups [3,4]; female doctors' "third sex" stigma[5] ; as well as the studies by Taiwan scholars, such as stigma of the brides from Chinese mainland and middle school students' "sissy" stigma.

Among researches on stigma, there are also some conducted targeting college students, for example, Bowell finds that Obama's regime has a positive impact on the identity of black college students; Eider compares the stigmatization phenomenon present in the lower social class groups between state universities and private universities. In China, Chou Fang sums up the stigma behaviors among college students; in addition, "problem students” stigmas as well as college students' crime stigma have also been discussed.

Different from the college students' stigma caused by races or classes in Western countries, the huge gap between China's private and public higher education often makes the private college students present a lowered self-esteem [6], private colleges students are suffering social rejection and discrimination from society and themselves, i.e. stigmatization process. So far, however, there has been no research targeting this group of people, and there is also a lack of effective instrument that measures the degree of their stigma, the present study precisely meets such development needs for the study of localization.

\section{Development of Questionnaire on Private College Students' Identity Stigma}

\subsection{Overview of research on construction of stigma questionnaire dimensions}

Over decades of stigma research development at home and abroad, stigma structure and evaluation have presented a trend of diversification. Pinel's Stigma Consciousness Questionnaire (SCQ) includes two 
dimensions: stigmatized groups' unfair perception of discrimination, and their own discrimination experience[7] . Vogel et al. focus on the cause of stigma, they believe that stigma can be divided into two dimensions, public stigma and self-stigma, of which, public stigma includes stereotype, discrimination and prejudice[8], while self-stigma is mainly about the self-efficacy and self-esteem after the stigma internalization. Internalized stigma questionnaire of mental illness developed by Jennifer et al. which has four dimensions: social withdrawal, alienation, discrimination perception and stereotype. Weiss believes that stigma should include three dimensions: stigma perception, self-stigma and discrimination experience; Discrimination and Stigma Scale (DISC-12) on mental disorders developed by Thornicroft includes four dimensions: unfair perception, drawback behavior, stigma \& discrimination resistance and active support.

Qian Sheng and Wang Wenxia believe that college students' HIV stigma questionnaire should include three dimensions: social distance, moral judgment blame and mandatory treatment advice; Hao Zhihong and Liang Baoyong develop a professional psychological help seeking stigma questionnaire, which comes out with four dimensions after integrating public stigma and self-stigma scales: self-awareness of the need for psychological help, tolerance to humiliation, interpersonal openness and confidence toward mental health experts. The adolescents' online stigmatization questionnaire developed by Lei Li et al. contains six dimensions: social isolation, stereotype, identity impairment, discrimination experience, stigma perception and internalized stigma.

\subsection{Formation of initial questionnaire}

On the basis of literature analysis and relevant questionnaires, interview outline was developed. A total of 40 students, 5 boys and 5 girls each from freshman to senior grades, were interviewed, the contents were: (1) say what you know about the society's views on private colleges and private college students; (2) describe your psychological experience after admitted to private colleges; (3) what are the differences between private college and public college students, etc. According to the interview results, the identity stigma of private college students included the following four major dimensions: stereotype, internalized stigma, stigma resistance and withdrawal behavior.

Combining the analyses of literature and interview data, the authors summarized the institution, dimension and operational definition of private college students' identity stigma questionnaire. Specific contents are shown in Table 1.Meanwhile, modification was made to the initial questionnaire from the aspects that whether the entry reflected the contents of private college students' stigma concept, whether the statement of item was ambiguous, and whether they were easy to understand, ultimately, an initial questionnaire with 66 entries was formed. Among them, the stereotype dimension contained 19 items; withdrawal behavior dimension contained 11 items; internalized stigma dimension contained 23 items; and stigma resistance dimension 13 items. Questionnaire was scored by 1-5 points from "totally disagree" to "totally agree" using Likert 5 point scale, the questionnaire included the pros and cons topics.

\section{Dimensions of Private College Students' Identity Stigma Questionnaire and Confirmation of Reliability and Validity}

\subsection{Dimensions and items of the questionnaire}

A self-compiled questionnaire on private college students' identity stigma consisting of 66 items was used, the questionnaire was scored on 5 point scale; General Self-Efficacy Scale (GSES), this questionnaire was scored using a 4 point system. Group measurement was carried out using the unified guidance language taking class as the unit, questionnaires were collected on site after filling out.Samples were collected from students of multiple specialties such as liberal arts, economics \& management and science \& engineering of the Sunshine College, subjects were distributed in grades 1-4. Initial questionnaire: a total of 534 valid samples were collected. Among them, 269 were boys (50.3\%), 265 were girls (49.7\%); 105 were freshmen (19.6\%), 210 were sophomores (39.3\%), 93 were juniors (17.4\%), and 127 seniors (23.7\%). 
Table 1 Structure and dimension definition of private college students' identity stigma questionnaire

\begin{tabular}{|l|l|l|}
\hline Dimension & Dimension & Example \\
\hline Stereotype & $\begin{array}{l}\text { Public's behavior of putting a label on a group, through such } \\
\text { a process, public forms a stereotype, those being labeled are } \\
\text { considered to be different from those not being labeled. }\end{array}$ & $\begin{array}{l}\text { Less opportunity for practice, lazy, poor } \\
\text { learning ability, no room for development, } \\
\text { poor overall quality, etc. }\end{array}$ \\
\hline $\begin{array}{l}\text { Withdrawal } \\
\text { behavior }\end{array}$ & $\begin{array}{l}\text { After individuals experience discrimination, as they accept } \\
\text { the out group's stereotype on them, they recognize and } \\
\text { accept the stigma and internalize them into their own } \\
\text { characteristics, under such circumstances, the individuals } \\
\text { have a sense of social alienation, thus resulting in } \\
\text { psychological and behavioral withdrawal behavior. }\end{array}$ & $\begin{array}{l}\text { Embarrassed to say that they are private } \\
\text { college students, cover up the fact that } \\
\text { they are private college students, etc. }\end{array}$ \\
\hline $\begin{array}{l}\text { Internalized } \\
\text { stigma }\end{array}$ & $\begin{array}{l}\text { The stigmatized individuals accept the out group's } \\
\text { stereotype on them, that is, accept the characteristics and } \\
\text { attributes of the group they belong recognize and accept the } \\
\text { stigma and internalize them into their own characteristics. }\end{array}$ & $\begin{array}{l}\text { Consider the education they receive is not } \\
\text { as good as others, consider themselves as a } \\
\text { members, feel they have beenshame to } \\
\text { family looked down upon, etc. }\end{array}$ \\
\hline $\begin{array}{l}\text { Stigma } \\
\text { resistance }\end{array}$ & $\begin{array}{l}\text { The individuals bearing stigma use different strategies to } \\
\text { resist the derogatory label gives them, such strategies can be } \\
\text { actions or society psychological self-persuasion. }\end{array}$ & $\begin{array}{l}\text { Do not feel inferior because they are } \\
\text { private college students, do not fear to } \\
\text { compete with public college students }\end{array}$ \\
\hline
\end{tabular}

The results were statistically analyzed by SPSS18.0 and AMOS17.0 software. Item analysis was performed by using correlation method and Critical Ratio (CR) values, items with overall correlation coefficient less than 0.30 or non-significant critical values were deleted, the analysis results showed that the deleted items were B3, D7 and D9, while other items were retained.

EFA was performed on the remaining 63 items; factors were extracted by principal component analysis and rotated by maximum equilibrium method for a total of three times. 27 items were removed in the first analysis; in the second analysis, 6 items were removed, KMO values of the pretest data samples were all higher than 0.90; KMO value was 0.928 for the third factor analysis, $\chi^{2}$ value of Bartlett's Spherical test was 7869.527, $d f=435$, and significance level was less than 0.001 , indicating that the data were suitable for factor analysis. Finally, a stable factor structure was obtained, 30 items in next formal investigation, the entire items explained $55.30 \%$ of variation, showing good EFA results,.

Based on the EFA results, a formal questionnaire on private college students' self-identity stigma was formed by rearrangement of items. Fitting was performed on the conceived dimension model using AMOS software, the results showed $\chi^{2}$ value of $894.484, d f$ value of $399, \chi 2 / d f$ value of $2.241<5$, GFI, AGFI, CFI, IFI, TLI values were all higher than 0.80 , RMSEA value was 0.062 , the fitting results of the model indicated that it could relatively well support the preconceived dimensions. Furthermore, the loads of items were all above 0.40 except for item 3 in the withdrawal behavior dimension.

Table 2 Model fitting indices for private college students' self-identity stigma questionnaire

\begin{tabular}{clllllllll}
\hline Model index & $\chi^{2}$ & $d f$ & $\chi^{2} / d f$ & GFI & AGFI & CFI & IFI & TLI & RMSEA \\
\hline Fitting & 894.484 & 399 & 2.241 & 0.841 & 0.815 & 0.858 & 0.860 & 0.845 & 0.062 \\
\hline
\end{tabular}

\subsection{Questionnaire reliability and validity analysis}

Internal consistency reliability of the questionnaire was estimated using $\alpha$ coefficient, and 50 students in the samples were randomly selected for re-test four weeks after the previous test, in order to test the test-retest reliability of the questionnaire, the reliability analysis results (see Table 3) showed that the private college students' identity stigma had relatively good time stability, and relatively strong homogeneity, the measured scores were reliable.

The validity analysis included content validity, structure validity and empirical validity. The content and accuracy of language expression of each item were validated by experts, which can basically well reflect the contents to be measured. Besides, EFA results showed that each item of the questionnaire can gather in accordance with the conception of dimensions under mandatory four factors, explaining $55.30 \%$ of the variation, CFA can relatively well support the results of EFA. Calculation of the correlation coefficient for each dimension and the correlation coefficient with total questionnaire showed that total scores between dimensions were highly correlated (see Table3), there also existed significant correlations between the 
dimensions, and therefore, the questionnaire was considered to have relatively good internal structure validity. GSES was adopted as the criterion of the questionnaire, the results showed that the correlation between self-identity stigma score and self-efficacy scale was $-.146(\mathrm{P}<0.01)$, indicating relatively good empirical validity of the questionnaire.

Table 3 Reliability and Validity of private college students’ stigma questionnaire

\begin{tabular}{|l|l|l|l|l|l|}
\hline Item & Stereotype & $\begin{array}{l}\text { Stigma } \\
\text { resistance }\end{array}$ & Internalized stigma & $\begin{array}{l}\text { Withdrawal } \\
\text { behavior }\end{array}$ & Total questionnaire \\
\hline Number of items & 11 & 9 & 5 & 5 & 30 \\
\hline$\alpha$ coefficient & 0.87 & 0.84 & 0.69 & 0.73 & 0.73 \\
\hline Split-half reliability & 0.86 & 0.85 & 0.65 & 0.71 & 0.67 \\
\hline $\begin{array}{l}\text { Test-retest } \\
\text { reliability }\end{array}$ & 0.81 & 0.86 & 0.71 & 0.78 & 0.73 \\
\hline Stereotype & 1 & & & & \\
\hline Stigma resistance & $0.11^{* *}$ & 1 & & & \\
\hline Internalized stigma & $0.67^{* *}$ & $0.29^{* * *}$ & 1 & & \\
\hline $\begin{array}{l}\text { Withdrawal } \\
\text { behavior }\end{array}$ & $0.47^{* *}$ & $0.43^{* *}$ & $0.65^{* *}$ & 1 & \\
\hline Total score & $0.78^{* *}$ & $0.68^{* *}$ & $0.81^{* *}$ & $0.78^{* *}$ & 1 \\
\hline
\end{tabular}

\section{The Survey of Private College Students' Identity Stigma}

\subsection{Participants and procedure}

The participants in this study were recruited through a web-based survey. The survey was put on a website named "Questionnaire Star", the web link was given to the three private colleges(Xiamen Jiageng College, Fuzhou Zhicheng College, and Yango College ) through the Students' office of each, all the participant were volunteered and got prized by the website randomly when they submit the answer. Total of 895 valid samples were collected. Among them, 340 were boys (37.9\%), 555 were girls (62.1\%); their ages ranged from 18 to 24, with a mean of 19.30 years (SD 1.23). There were 456 first-year students (51\%), 263 sophomores (29.4\%), 122juniors (13.6\%), and 54 seniors (6.0\%).

\subsection{Results}

Participants reported relatively high level of stigma $(M=109.21, S D=16.91$; full score is 150), reflecting their beliefs that they were probably suffering from the discrimination. We also examined whether the gender affected the private identity stigma by conducting independent $t$ tests on four dimensions and the total scores. As can be seen in the Table 4, There was a medium gender difference on the total score $(p=0.009)$, but this difference was not replicated in all dimensions.

Table 4 Means, Standard Deviations, and t-test of the gender on dimensions

\begin{tabular}{|c|c|c|c|c|c|c|}
\hline Dimensions & \multicolumn{2}{|c|}{ Male } & \multicolumn{2}{c|}{ Female } & $t$ & $p$ \\
\hline Stereotype & 18.69 & 3.29 & 20.53 & 3.57 & $-3.62^{* * *}$ & 0.000 \\
\hline $\begin{array}{c}\text { Withdrawal } \\
\text { behavior }\end{array}$ & 32.83 & 6.87 & 32.37 & 6.48 & 0.26 & 0.796 \\
\hline $\begin{array}{c}\text { Internalized } \\
\text { stigma }\end{array}$ & 17.29 & 2.51 & 19.37 & 3.44 & $-3.88^{* * *}$ & 0.000 \\
\hline $\begin{array}{c}\text { Stigma } \\
\text { resistance }\end{array}$ & 38.93 & 6.62 & 38.40 & 6.48 & 0.98 & 0.326 \\
\hline Total Scores & 107.74 & 15.61 & 110.67 & 17.57 & $2.67^{* *}$ & 0.009 \\
\hline
\end{tabular}

Note: ** $\mathrm{p}<01$; *** $\mathrm{p}<001$. 


\section{Discussion}

As an important part of China's higher education, private colleges have achieved great development in the past decade. However, currently, pupils of private education can hardly compete with public colleges in terms of educational attainments level and self-quality, moreover, private education is privately financed and operated, they have no ready-to-follow path of development, their management system is not yet perfect, and hardware facilities and software resources are lagged behind, all of which have led to low recognition and reputation of private colleges in the society, which have also brought private college students greater psychological pressure and distress. China's current national conditions determine the society's stereotype on private college students, the presence of private college students' public stigma does have its objectivity.

As expected, the results of our survey did show the identity stigma of being private college students. Both male and female students experience considerably high level of the whole identity sigma. However, female students in comparison to male ones suffered more on Stereotype and Internalized Stigma dimensions.

Gan Ian believes that stigma is an outside-to-inside process; Vowel's study also confirms that the public stigma can predict the formation of self-stigma, under such premise; members of stigmatized groups might gradually internalize the stigma while showing withdrawal behavior, or have a positive stigma resistance when faced with public stigma, thereby eventually forming a complete experience of identity stigma. Of course, withdrawal behavior and stigma resistance are not entirely contradictory, the two can co-exist at the same time, but the cause for differences in the stigma experience among individuals of identity stigmatized groups needs further exploration.

In China, studies targeting the local Chinese stigmatized groups, especially on the groups stigmatized due to a particular identity are still scant. Since this type of groups are not associated with diseases, the harmfulness of their stigma generally receives little attention by mainstream, but the influence of such stigma may be stronger, so the emphasis on vulnerable groups with Chinese characteristics is the future direction of stigma research. The questionnaire complied in this study provides a reference measuring tool for stigma quantification in future research on other identity stigmatized groups. Nevertheless, there are some limitations to the findings in this article that need to be considered for future research. We only discussed the difference between the genders, nevertheless, the grades and majors and major, the quality of private college and the career prospects are all supposed to discuss.

\section{Conclusion}

The intent of this study is to develop an instrument to measure identity stigma of private college students and find out the stigma situation of being private college students in Fujian. To that extent, the researcher follow the standard process to develop the questionnaire with 4 dimensions include: Stereotype, Internalized Stigma, Withdrawal Behavior and Stigma Resistance. The PCSISQ has good reliability and validity. The survey conducted in Fujian by using PCSISQ shows that the private college students are suffering the identity stigma, which has implications for the education policy maker and educators to give more focus to the private college students, furthermore, efforts should also be at individual, institutional and social level to minimize the effect of identity stigma.

\section{References}

[1]. Goffman and Song Lihong, Stigma—Notes on Damaged Identity Management, Beijing: The Commercial Press, 2009, pp. 1-2.

[2]. Guan Jian, "Stigma: The Current Research and the Static-Dynamic Model”, Journal of Educational Science of Hunan Normal University, vol.6, pp.80-84, 2007.

[3]. Guan Jian, "Construction and social representation of identity stigma - A case study of immigrant workers in jurisdiction scope N of Tianjin”, Youth Studies, pp.35-38, 2006. 
[4]. Guan Jian, “The Concept Development of Stigma and the Construction of Multiple Levels Conceptual Framework”, Journal of Nankai university, vol.5, pp. 126-134, 2007.

[5]. Xu Xiping and Zhu Wei, "Social psychological analysis on female doctors' 'third gender'”. Theory Learning, pp.1002-2589, 2011.

[6]. Wang Wenbin, Comparative Study on level of self-esteem and mental health between the students in public colleges and private colleges, Master's thesis, Shandong Normal University, 2008.

[7]. Elizabeth C. Pinel, "Stigma Consciousness: The Psychological Legacy of Social Stereotypes”, Journal of Personality and Social Psychology, vol.1, pp.114-128, 1999.

[8]. David L. Vogel et.al, “Is Stigma Internalized? The Longitudinal Impact of Public Stigma on Self-Stigma”, Journal of Counselling Psychology, vol.60, pp.311-316, 2013. 